\title{
Initial study of the Coix lachryma-jobi application in reducing algal growth in eutrophic lake
}

\author{
Rofiq Iqbal $^{l *}$, Teddy Tedjakusuma ${ }^{2}$, and Dhimas Dwinandha ${ }^{3}$ \\ 1,2,3Water \& Wastewater Research Group, Fac. of Civil \& Env. Eng., Institut Teknologi Bandung, Jl. Ganesha 10 Bandung, Indonesia
}

\begin{abstract}
The usage of Hordeum vulgare or barley straw as an algistatic to control eutrophication in lake has been applied in the United States and England. Inspired by barley straw, this research studied about Coix lachryma-jobi as a substitute for barley straw in Indonesia. The aim of this research is to determine the applicability of Coix lachryma-jobi product in reducing algal growth along with its interactions with the nutrients in the water. Two stages of experiment were conducted. The first stage was applying three different products of Coix lachryma-jobi (powder, chop, and straw) in the reactors filled with water from Domestic Wastewater Treatment Plant as a representation of hypertrophic water body. Then the chlorophyll concentration was monitored to indicate algal growth. Another experiment was applying Coix lachrymajobi in the reactor filled with tap water and water sample. The result of the experiments show that the straw of Coix lachryma-jobi without further physical treatment is the most effective to reduce algae population in the water. However, the mechanism of the algal growth has not been affected by the interactions between Coix lachryma-jobi and the nutrients.
\end{abstract}

\section{Introduction}

There are many ways to define "eutrophication", but it is widely known as a condition of an excessive amount of nutrients, mainly consist of phosphorus $(\mathrm{P})$ and nitrogen $(\mathrm{N})$, which is caused by anthropogenic activity. The eutrophic condition allows algae to grow rapidly, causing an "algal-blooming". As a result, the water quality in many aquatic ecosystems is greatly regressed because some simultaneous problems are occurred during the situation.

As the problems persist, some countries have their own solution of eutrophication. The use of barley straw is one of the popular solutions that widely known in United States (US) and United Kingdom (UK). Barley straw is a local plant from the grain family (Poaceae) with Hordeum vulgare as a nomenclature name. In various studies, this plant has proven to control eutrophication as an algistatic or inhibiting algal growth [1]. This is because barley decomposes in aerobic conditions so that phenol compounds such as lignin are dissolved in water bodies thereby inhibiting the algal growth [2]. Various eutrophication control trials had shown success for more than six consecutive years, without the influence of resistant algae, without any negative impact on invertebrates, fish, and plankton. The first study to prove the effectiveness of barley straw's use was conducted by Street in 1977 [3]. Similar studies in the following years showed supportive results as well, which showed that barley straw can be used in controlling eutrophication on a laboratory scale $[4,5]$ and on a field scale $[3,6]$.
The success of barley straw in controlling algalbloom inspired this study in Indonesia. Due to the biodiversity difference of the country, barley straw does not grow naturally in Indonesia. Therefore, the application of Hordeum vulgare plant as a controller of eutrophication was replaced by Coix lachryma-jobi plants as an alternative species in Indonesia. Coix lachryma-jobi is chosen because it is belonged to the grain family (Poaceae), as well, similar to Hordeum vulgare. Coix lachryma-jobi originates and grows wild in West Java and known by the locals as Hanjeli. This plant is a grass which bears fruit with a hard-white shell and has an oval shape commonly used for jewellery, food, and medicine.

This is an initial study to determine which product is the most effective to reduce algae population and the impact of Coix lachryma-jobi to the nutrient's concentration in the water.

\section{Methodology}

\subsection{Preparation}

A total of $60 \mathrm{~L}$ sample was taken from Bojongsoang Wastewater Treatment Plant (WWTP) in Bojongsoang Subdistrict, Bandung, to represent the condition of eutrophication in a water body. On the other hand, Coix lachryma-jobi plant was taken in Ciwidey, West Java, Indonesia. The laboratory analysis then was conducted at the Water Quality Laboratory and Hydraulics

* Corresponding author: iqbal@tl.itb.ac.id 
Laboratory, Faculty of Civil and Environmental Engineering, Institut Teknologi Bandung.

The collected plant was dried up in the oven for 24 hours. After that, the plant was treated in three different way to get three kind of products. Firstly, some of the plant were crushed until it became a fine powder by mechanical grinder, then stored in a tea bag. Secondly, the plant was chopped roughly, and the last the plant just left as it is without any mechanical treatment. All the products then weighed and soaked in the water for another 24 hours as an acclimatisation process to decompose the plant before releasing the algistatic compounds [3]. Next, the products were strained and used in the reactors.

The reactors used were five glass boxes in size $30 \mathrm{x}$ $30 \times 30 \mathrm{~cm} 3$ each or $27 \mathrm{~L}$ of the total capacity each tank. The tanks were adjusted to mimic the environment conditions that support algae life by providing the aeration by an aquarium pump and illuminated by 4600 lux of fluorescent lights. The ratio of Coix lachryma-jobi used in this study were 0,135 grams of dry weight per litre water.

\subsection{First Stage Experiment}

Four tanks were filled with $15-\mathrm{L}$ water sample, then the water quality of samples was analysed and monitored through 3-day acclimatization to confirm that the algae lived in the tank could survive living in the artificial condition. Chemical oxygen demand (COD), nitrogen total kjedahl (NTK), nitrate $\left(\mathrm{NO}_{3}^{-}\right)$, nitrite $\left(\mathrm{NO}_{2}^{-}\right)$, ammonium $\left(\mathrm{NH}^{4+}\right)$, total phosphorus (TP), orthophosphate $\left(\mathrm{PO}_{4}{ }^{3-}\right)$, and chlorophyll were all monitored on daily basis. The concentration of chlorophyll was analysed to represent the number of algae that was still alive in the sample, as it is recommended in Standard Methods for the Examination of Water and Wastewater to estimate algal populations. Chlorophyll level is also a parameter that determine the trophic status of a water body in Regulation by Ministry of Environment of Republic of Indonesia [7], accounted for a minimum $0.2 \mathrm{mg} / \mathrm{l}$ ) of chlorophyll $\mathrm{A}$ for hypertrophic status.

After it was confirmed that the algae were still alive, the amount of nutrient were adjusted by adding the artificial nutrients to mimic the hypertrophic lake based on the Regulation by Ministry of Environment, with the average level of total $\mathrm{N}$ and $\mathrm{P}$ is more than $1.9 \mathrm{mg} / \mathrm{L}$ and $0.1 \mathrm{mg} / \mathrm{L}$ respectively. The artificial nutrients were derived from chemicals, which were potassium nitrate $\left(\mathrm{KNO}_{3}\right)$ to get the nitrate species, potassium nitrite $\left(\mathrm{KNO}_{2}\right)$ for nitrite, ammonium chloride $\left(\mathrm{NH}_{4} \mathrm{Cl}\right)$ for ammonium, and potassium phosphate $\left(\mathrm{K}_{3} \mathrm{PO}_{4}\right)$ for phosphate.

Subsequently, Coix lachryma-jobi were inserted in the tanks by a variation showed in Table 1 . Then the monitoring was repeated in 16 days. In this stage, only chlorophyll that were being monitored to measure the effect of Coix lachryma-jobi in reducing algae concentration. Table 1 sums up the first-stage experiment in this study.
Table 1. Summary of first-stage experiment.

\begin{tabular}{|c|c|c|c|c|}
\hline \multirow[b]{2}{*}{ No. } & \multicolumn{3}{|c|}{ Approach } & \multirow[b]{2}{*}{ Note } \\
\hline & $\begin{array}{c}\text { Environment } \\
\text { Condition }\end{array}$ & $\begin{array}{c}\text { Dose of } \\
\text { Coix } \\
\text { lachryma- } \\
\text { jobi } \\
\end{array}$ & $\begin{array}{c}\text { Type of Coix } \\
\text { lachryma- } \\
\text { jobi product }\end{array}$ & \\
\hline 1 & \multirow{4}{*}{$\begin{array}{l}4600 \text { lux } \\
\text { illumination, } \\
\text { aeration by } \\
\text { aquarium } \\
\text { pump }\end{array}$} & \multirow{4}{*}{$\begin{array}{c}0.135 \mathrm{~g} \text { dry } \\
\text { weight } / \mathrm{L} \\
\text { water }\end{array}$} & - & $\begin{array}{c}\text { Control } \\
\text { tank }\end{array}$ \\
\hline 2 & & & Powder & - \\
\hline 3 & & & Chop & - \\
\hline 4 & & & Straw & - \\
\hline
\end{tabular}

\subsection{Second Stage Experiment}

This stage only worked with three tanks, two of them were reactor 1 and 4 , with the aim to learn about the interaction of the Coix lachryma-jobi with the nutrient in the water. The procedures and environments were similar to the first stage experiment, but instead of chlorophyll, the nutrients level was monitored through the process. In addition, tap water was used in the third tanks to eliminate the algae interaction with the plant. The water quality in the tank was adjusted to mimic the hypertrophic water body based on the aforementioned regulation. Type of Coix lachryma-jobi product used in this stage was the most effective product from the prior experiments. Table 2 presents the summary of this experiment.

Table 2. Summary of second-stage experiment.

\begin{tabular}{|c|c|c|c|}
\hline \multirow{2}{*}{ No. } & \multicolumn{2}{|c|}{ Approach* } & \multirow{2}{*}{ Note } \\
\cline { 2 - 3 } & $\begin{array}{c}\text { Type of Coix } \\
\text { lachryma- } \\
\text { jobi } \text { product }\end{array}$ & $\begin{array}{c}\text { Presence } \\
\text { of Algae }\end{array}$ & \\
\hline 1 & - & Yes & $\begin{array}{c}\text { Control tank filled } \\
\text { with water sample }\end{array}$ \\
\hline 4 & $\begin{array}{c}\text { To be } \\
\text { decided }\end{array}$ & Yes & $\begin{array}{c}\text { Filled with water } \\
\text { sample }\end{array}$ \\
\hline 5 & $\begin{array}{c}\text { To be } \\
\text { decided }\end{array}$ & No & $\begin{array}{c}\text { Filled with tap } \\
\text { water }\end{array}$ \\
\hline
\end{tabular}

*Environment condition follows those from first stage experiment, i.e. with 4600 lux illumination, aeration by aquarium pump, and $0.135 \mathrm{~g}$ dry weight/L water dose of Coix lachryma-jobi.

\section{Result and Discussion}

\subsection{Initial Characterisation of Sample}

The sample was taken in maturation pond mixed with facultative pond of Bojongsoang Wastewater Treatment Plant to get a simulation of algal-blooming in hypertrophic water body. The ponds were selected due to the high concentration of algae (indicated by green colour in the water). The water quality analysis was conducted subsequently to determine the pollution level or trophic level status of the sample. The result of the analysis is shown in Table 3 . From the table, it can be 
concluded that the sample condition had satisfy the hypertrophic criteria, as intended.

Table 3. Sample conditions

\begin{tabular}{|c|l|c|c|}
\hline No. & Parameters & $\begin{array}{c}\text { Concentration } \\
(\mathrm{mg} / \mathrm{L})\end{array}$ & $\begin{array}{c}\text { Hypertrophic Lake } \\
\text { Standard* (mg/L) }\end{array}$ \\
\hline 1 & Nitrate & 0.06 & - \\
\hline 2 & Nitrite & 0.14 & - \\
\hline 3 & Ammonium & 0.11 & - \\
\hline 4 & $\begin{array}{l}\text { Total } \\
\text { Nitrogen }\end{array}$ & 47.34 & $>1.9$ \\
\hline 5 & $\begin{array}{l}\text { Total } \\
\text { Phosphate }\end{array}$ & 0.78 & $>0.1$ \\
\hline
\end{tabular}

*Hypertrophic status of a water body in Regulation by Ministry of Environment of Republic of Indonesia [7]

\subsection{First Stage of Experiment - Determining the Most Effective Product of Coix lachryma-jobi}

This experiment was focused on finding the type of Coix lachryma-jobi product that effectively reduced the algae concentration in the sample. It was expected that each product would gave different results due to the different physical structures hence altered the interaction the plant with the algae.

Figure 1 depicts the result of the first-stage experiment. As shown, the first 8-day running time displayed a similar trend from all reactors, which were a surge in until around second day, then there was a relatively significant drop in concentration until the sixth day. On the day- 6 , the chlorophyll concentration in Reactor 4 had reached zero, while other reactors only reached zero around day- 8 . This was remained until around day-12. On the day-12 and further, there was a different situation occurred in the reactors. A relatively significant algal growth had shown in Reactor 1, 2, and 3 , but it was the opposite in Reactor 4. Instead, Reactor 4 only showed a slight increase in the concentration.

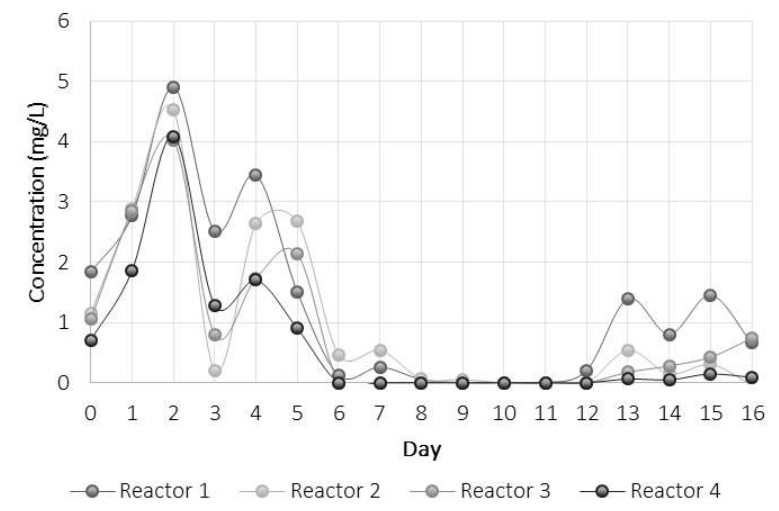

Fig. 1. Chlorophyll concentration changes per day in the firststage experiment

While being a control tank without added Coix lachryma-jobi, Reactor 1 showed a similar stage in chlorophyll concentration changes. Without the plant and feed from the outside, it is safe to say that only the nutrients dynamic can impact to the algal growth. Through the day, the algae were growing while the nutrients were decreasing. On the second day, algae population had reached its maximum and the nutrients concentration was not sufficient anymore. As the result, the algae population dropped and went to zero on day-8. This phase occurred for approximately four days. During this phase, the algae was decomposed releasing some nutrients back in the water. On the day-12 until day 16 , the algae population slowly rose again due to the presence of nutrients in the water from the preceding algae decomposition.

From the graph it can be concluded that Reactor 4 gave a promising result compared to the others. Based on the barley straw research by Geiger et al. [3], barley straw may release some phenolic compounds such as lignin and especially oxidised phenolics under aerobic condition. This occurred both before and after decomposing and it had been proven that both conditions can suppress algal growth $[2,5]$. Adapting the theory on this study, the powdered Coix lachryma-jobi, may had been massively decomposed before the application in the Reactor 2, resulting in the release of phenolic compounds earlier than the other two products. This is due to the powdered material has a large particle surface area, so the decomposition occurs faster. When being applied in the reactor, the powder had lost a significant amount of phenolics compounds, thus lowered the algistatic capacity of the plant. This case could explain the chopped Coix lachryma-jobi, as well.

On the contrary, the straw Coix lachryma-jobi without further treatment underwent a decent amount of decomposition so the phenolic compounds could be retained in a desirable level to reduce algae population and lasted until the end of running time. This concludes that the dry Coix lachryma-jobi without any further treatment was the most effective product to reduce algal growth.

\subsection{Second Stage of Experiment - Analysing Nutrients Interactions with Coix lachryma-jobi}

This stage was focused on analysing Coix lachryma-jobi effects on nutrients concentration. This used the straw Coix lachryma-jobi as the inhibitor. It was predicted that the presence of Coix lachryma-jobi could reduce the nutrients level thus affected the algae growth in the water.

Figure 2 to 7 reveal the result of the second-stage experiment.

The reason behind filling Reactor 5 with tap water was to exclude the algae interactions with Coix lachryma-jobi and the nutrients. This left the plant and the nutrients only so the interactions between both of which could be observed clearer. Reactor 1 was still used as a comparison with algae-nutrients interaction. 


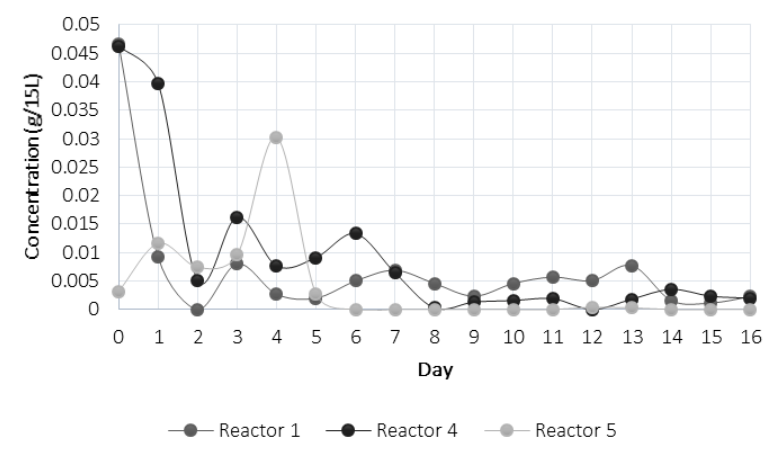

Fig. 2. Nitrate concentration changes per day in the secondstage experiment

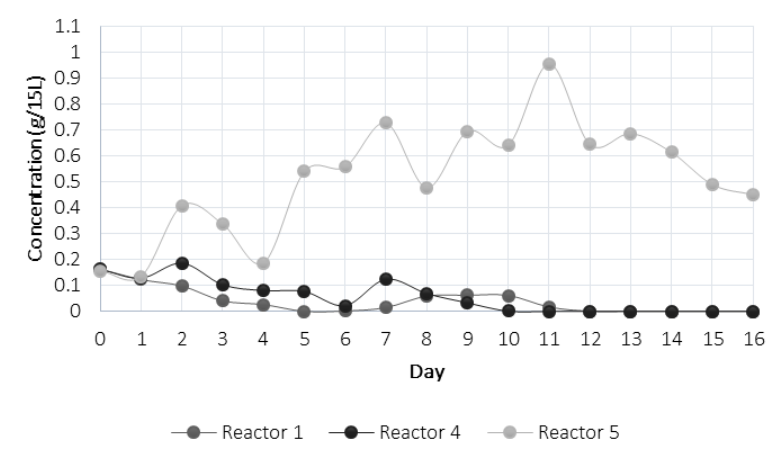

Fig. 3. Nitrite concentration changes per day in the secondstage experiment

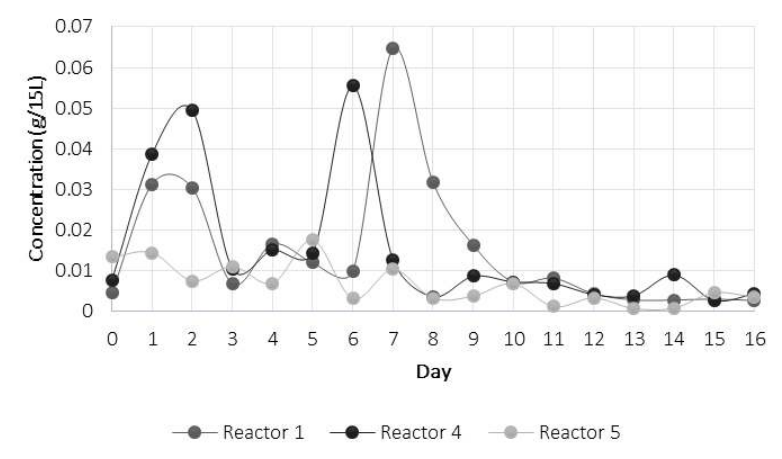

Fig. 4. Ammonium concentration changes per day in the second-stage experiment

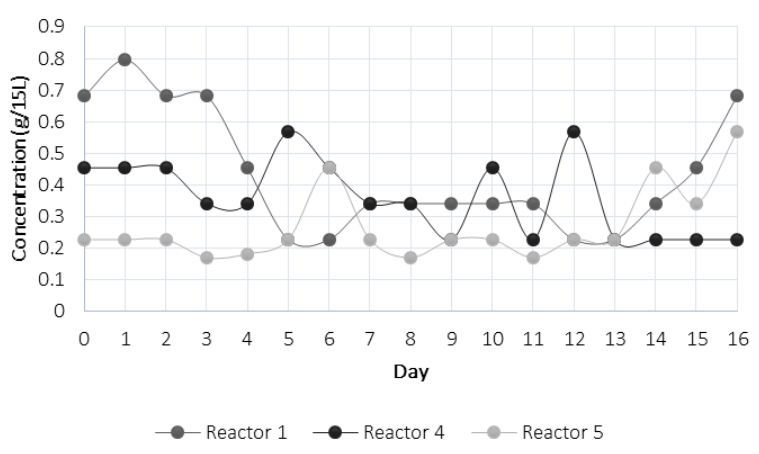

Fig. 5. Total nitrogen concentration changes per day in the second-stage experiment

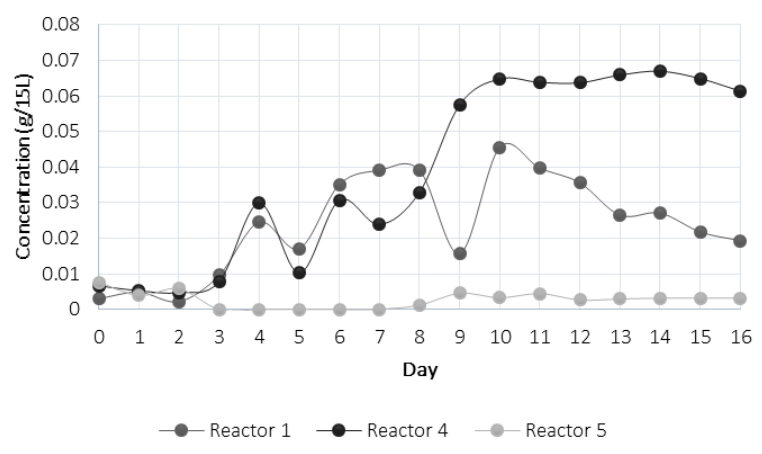

Fig. 6. Orthophosphate concentration changes per day in the second-stage experiment

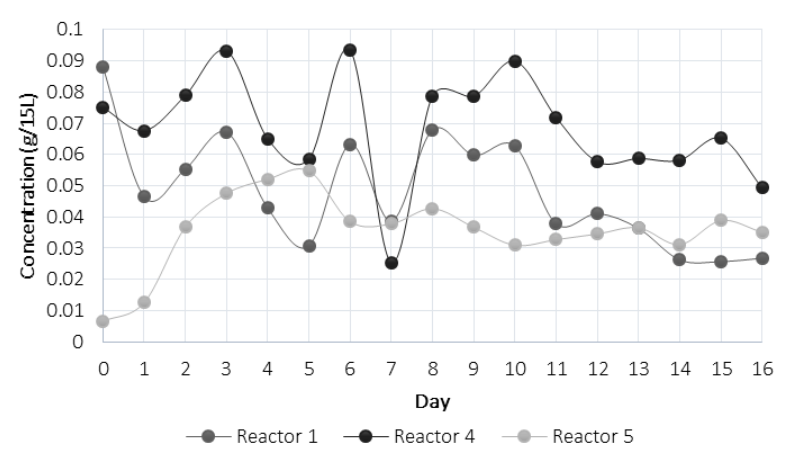

Fig. 7. Total phosphate concentration changes per day in the second-stage experiment

From Figure 2 to 7 it is shown that the experiment results could not portray the interactions between Coix lachryma-jobi and the nutrients. As shown in the graphs, the nutrients concentrations were highly fluctuated during the running period and did not show any tendency. In fact, it is similar to the barley straw research, as some research could not agree with the actual interactions of barley straw with the nutrients. As mentioned by Welch, et al. [6], they did not find any differences in concentrations of suspended reactive phosphorous, ammonium, or nitrate between a treated and non-treated section of a canal, yet, algal growth inhibition occurred in the treated section. This research also confirmed with the research from Gibson, et al. [4], where they added a substantial amount of $\mathrm{N}$ and $\mathrm{P}$ to an algae culture treated with barley liquor and the algal growth inhibition still occurred

\section{Conclusion}

This study concludes that the straw Coix lachryma-jobi without further physical treatment is the most effective to reduce algae population in the water. While proven to be an algistatic, the mechanism of the algae growth has not been affected by the interactions between Coix lachryma-jobi and the nutrients. 


\section{References}

1. Boylan, J. D. Advancements of Determining the Role of Barley Straw as an Alga Control AgentNotes. (University Department of Animal Ecology, Iowa University, 2000)

2. Everall, N.C. and D.R. Lees. Water Research Journal, 31 (1997).

3. Geiger, S., Henry, E., Hayes, Pat., Haggard, K. Barley Straw - Algae Control Literature Analysis. (Portland University Aquatic Scientific, USA, 2005)

4. Gibson, M. T., I. M. Welch, P. R. F. Barrett, and I. Ridge. J. Appl. Phycol. 2, 3 (1990)

5. Pillinger, J.M. Journal of Chemical Ecology, 20, 7 (1994).

6. Welch, I. M. P. R. F. Barrett, M. T. Gibson, and I. Ridge. J. Appl. Phycol 2, 3 (1990).

7. Ministry of Environment of the Republic of Indonesia. Permen LH 28 (2009) 